\title{
AN ANALYSIS OF THE LONGITUDINAL MEASUREMENT INVARIANCE OF THE SOCIAL PRESENCE SCALE DEVELOPED FOR OPEN AND DISTANCE LEARNING ENVIRONMENTS
}

\author{
Dr. Murat Dogan SAHIN \\ ORCID: 0000-0002-2174-8443 \\ Faculty of Education \\ Anadolu University \\ Eskisehir, TURKEY \\ Dr. Hakan KILINC \\ ORCID: 0000-0002-4301-1370 \\ Open Education Faculty \\ Anadolu University \\ Eskisehir, TURKEY \\ Dr. Hakan ALTINPULLUK \\ ORCID: 0000-0003-4701-1949 \\ Open Education Faculty \\ Anadolu University \\ Eskisehir, TURKEY
}

Received: 05/10/2019 Accepted: 09/06/2020

\begin{abstract}
As with all fields of social sciences, open and distance learning studies frequently use self-reports in their collection of data. Similarly, as with all measurement tools, proof of construct validity through statistical processes is important for testing hypotheses based on the findings, making decisions, and essentially ensuring the tools and methods used are fit for purpose. During construct validity testing processes, the reporting of findings regarding measurement invariance of a scale is an important element that is often neglected. This study aims to portray the longitudinal invariance of the Social Presence Scale (Cakmak, Cebi \& Kan, 2014), which is frequently used to determine the social presence in open and distance learning environments research and has confirmed construct validity in the literature, through repeated measurements obtained in an experimental study. This research was conducted on 280 learners in a 3-month interval. The data gathered was analyzed for measurement invariance using the Mplus 7.0 software package in accordance with the four stages described in the literature. The measurement invariance tested in each stage were studied for $\triangle \mathrm{CFI}$, and $\triangle$ RMSEA values in addition to likelihood chi-square. The findings indicate the conditions required for measurement invariance in each stage, or in other words, the longitudinal invariance of the scale was achieved. The findings of this study may provide a precedent for similar studies in the future.
\end{abstract}

Keywords: Measurement invariance, longitudinal data, confirmatory factor analysis, open and distance learning, social presence

\section{INTRODUCTION}

Stemming from computer-aided communication environments (Lowenthal, 2010) and an imperative element of online learning environments (Akcaoglu \& Lee, 2016), social presence is defined by Garrison (2011) as "Learners being able to adapt to the workgroup, communicate in a safe environment, and develop personal and emotional relationships in stages while reflecting their personalities".

The concept of social presence, which emphasizes the necessity for encouraging social interaction as a tool for directing learners towards critical thinking and higher-level learning (Garrison \& Akyol, 2013), has 
led researchers and practitioners to study not merely what social presence is, but also the roles it plays in online learning processes due to its direct relevance in online learning processes (Annand, 2011; Kreijns et al., 2014; Lowenthal, 2010; Oztok \& Brett, 2011). With these studies, it was determined that social presence influences various factors in the learning experiences of learners. The findings were that social presence may positively influence: participation and motivation to participate in learning processes (Jorge, 2010), satisfaction with the learning process (Cobb, 2009; Hostetter \& Busch, 2006; Richardson \& Swan, 2003; Strong et al., 2012), perceived learning (Hostetter, 2013; Joksimovic vd., 2015; Kang ve Im, 2013; Richardson ve Swan, 2003; Russo ve Benson, 2005), academic achievement (Joksimovic vd., 2015), and interaction levels (Boston vd., 2009). Similar to these results, a study by Richardson and Swan (2003) determined that learners with high levels of social presence perception in an online learning process had both higher satisfaction from the learning process, and greater perceived learning levels compared to learners with lower social presence.

As a fundamental requirement that ensures the synchronous implementation of many components such as instructors, learners, and content (Whiteside, 2015); knowing the positive and negative influences on social presence is seen as a guide for researchers who aim to increase social presence in learning processes. Considering an increase in the social presence levels of learners results in increased satisfaction regarding the online learning process (Borup et al., 2012; Horzum, 2015), it may be stated that designs that increase social presence levels are necessary. As such, designs that allow for interaction should be implemented (Kilinc, 2020). By portraying the individual personalities of learners in open and distance learning environments, allowing the development of personal and emotional relationships, the concept of social presence thereby minimizes the feeling of loneliness and studies indicate that it must be measured correctly and an action plan must be developed accordingly. In other words, studies show that the measurement of the social presence of learners must be conducted in accordance with the projected purpose of measurement. This can only be ensured with a high level of validity of the measurement tool being used. Thus, experimental studies may more accurately and reliably measure the influence of the experiment on social presence and ensure the researchers achieve more accurate findings based on these results.

\section{Research Purpose}

As with all fields of social sciences, self-reports are frequently used in the data gathering process of research in open and distance learning. As with all measurement tools, it may be stated that the statistical processes applied in determining construct validity in self-reports are highly important for establishing a basis for important issues such as testing a hypothesis based on the findings, or making important decisions based on these tools and methods by ensuring they are fit for purpose. When testing construct validity, exploratory factor analysis (EFA) is used when lacking a strong a priori regarding the construct while confirmatory factor analysis (CFA) is used in the presence of a strong a priori to test an existing model. Based on the findings regarding construct validity, the mean scores obtained from the scale may be used to compare groups or repeated measurements. However, in these instances throughout this process where the need to present evidence of construct validity is often overlooked is measurement invariance. As such, before comparing the measurements among different groups or among repeated measurements, the measurement tool must have proven to sustain the same factorial structure between these groups or repetitions.

The goal of this study is to portray the longitudinal invariance of the Social Presence Scale (Cakmak, Cebi \& Kan, 2014), which is frequently used to determine social presence levels in open and distance learning environments and has had its construct validity confirmed using CFA in previous studies in the literature (Elcicek, Erdemci ve Karal, 2018; Ercan ve Bulbul, 2019; Kilinc, 2020; Matanaghi, 2015), through repeated measurements conducted within the scope of an experimental study. The findings of this study are believed to provide an example for future research into an often neglected aspect of longitudinal studies in the future. 


\section{METHOD}

\section{Research Design}

This is a correlational study that aims to test the longitudinal invariance of the Social Presence Scale developed by Cakmak, Cebi and Kan (2014) based on repeated measurements conducted within the scope of an experimental study. To this end, the four stages of measurement invariance were tested. The first stage is the model-data fit test of the basic model. In each following stage, certain parameters for two groups/ measurements are fixed; forced into equal estimation. Thus, any significant reduction in model-data fit as the model is further restricted through each stage is determined (Widaman \& Reise, 1997). The details of measurement invariance and the procedures conducted within this study are explained in detail below.

\section{Measurement Invariance}

Measurement invariance may be defined as the measurement tool presenting the same structure, or same meaning, resulting from repeated applications on the same group or on groups differentiated based on a specific characteristic (Marsh, Parker \& Morin, 2015). In other words, measurement invariance is proving that the differentiation observed between groups or in repeating data sets regarding the quality being measured by the measurement tool is not caused by the measurement tool itself. A lack of measurement invariance results in ambiguity regarding the source of potential differences in measurement results: one cannot know if the differing results are due to the differences in measurements (repeated on the same group), the groups themselves, or measurement tool.

Traditional Confirmatory Factor Analysis (CFA) is not sufficient to ensure measurement invariance. To this end, advanced structural equation modelling methods are utilized. If the invariance of the scale in different groups is being studied, multi-group CFA is applied. If the scale is applied to the same group at certain time intervals, measurement invariance must also be ensured. This situation is called longitudinal invariance and is studied through the same invariance stages as multi-group applications; only invariance is tested for repeated measurements taken from the same individuals. Researchers in the field may have studied measurement invariance with different numbers of stages (e.g., Chen, Sousa, \& West, 2005; Cheung \& Rensvold, 1999; Ferrer, Balluerka, \& Widaman, 2008; Little, 1997; Millsap \& Meredith, 2007; Nesselroade, 1983; Rensvold \& Cheung, 1999), yet it may be stated that a consensus has been achieved on the four-stage approach (Basusta, 2010).

\section{Stages of Longitudinal Measurement Invariance}

The analysis of longitudinal measurement invariance consists of four stages. These stages are as follows in order of increasing restriction (Dimitrov, 2010; Putnick \& Bornstein, 2016; Widaman \& Reise, 1997):

Configural Invariance: In this model, no parameters are forced into equal estimation in repeated applications. Therefore, it is the most basic model. All parameters, for both groups or measurements, are estimated freely. If good fit values are obtained in this stage, the analysis progresses to the next stage. If the model-data fit indices are indicative of a poor fit, the analysis does not proceed to other stages and it is concluded that invariance cannot be obtained.

Metric Invariance: This analysis is conducted to show that the relationship between the latent variable and its indicators does not change with repeated measurements. As such, the factor loadings are restricted in repeated measurements; in other words, during measurements (regardless of how many measurements are conducted), equal estimation is forced. If the values that emerge with this restriction do not reveal worse fit than the first model, it is concluded that metric invariance is achieved. Otherwise, it is concluded that metric invariance cannot be ensured and the analysis does not progress to the next stage.

Scalar Invariance: In addition to the previous stage, the intercepts of the regression equation determined for the items are forced to equal estimation in measurements. If no significant degradation in the model emerges following the restriction, it is concluded that scalar invariance is achieved. 
Strict Invariance: This stage is directed at the item variances that are not shared with the latent variable and residual/error variances being stable in groups-measurements. As with other processes, the invariance is determined by comparison with the previous model. Some researchers state that strict invariance is not necessary in practice.

All of the aforementioned stages are summarized in the table 1 below.

Table 1. Fixed and freely estimated parameters in measurement invariance process

\begin{tabular}{cccc}
\hline Invariance Stage & Factor Loading & Intercepts & Residual Variances \\
\hline Configural & $*$ & $*$ & $*$ \\
Metric & Fixed & $*$ & $*$ \\
Scalar & Fixed & Fixed & $*$ \\
Strict & Fixed & Fixed & Fixed \\
\hline
\end{tabular}

Table 1. summarizes which parameters are forced into equal estimation in each stage, from the most general model to the most restricted model. In each invariance stage, values that are fixed for the measurements may be seen in the common factor model below.

\title{
Common Factor Model:
}

$$
Y=\tau+\lambda . n+\mathcal{E}
$$

\author{
Y: Observed Variable (Score of Person) \\ $\tau$ : Intercept \\ $\lambda$ : Factor Loading \\ $\boldsymbol{n}$ : Latent Characteristic of Individual Measured by Item \\ $\boldsymbol{\varepsilon}$ : Residual Variance
}

Measurement invariance is possible as long as the four invariance models explained in detail above are ensured. Stages following configural invariance are based on comparison with the previous model. As each model is nested in the previous, the change in the model fit is examined using a likelihood ratio chi-square difference test (Bentler \& Bonett, 1980). However, since likelihood ratio tests are sensitive to sample size, the change in model fit should also be evaluated based on the amount of change in fit indices (Widaman, Ferrer \& Conger, 2010) such as RMSEA and CFI. As such, analyzing the $\triangle$ CFI and $\triangle$ RMSEA values and considering values above .01 as significant has been proposed (Cheung \& Rensvold, 2002; Little 1997; Vandenberg \& Lance, 2000). In other words, a difference of more than .01 in RMSEA and CFI between two models is interpreted as a significant degradation in the model as a result of restriction, and that measurement invariance was not achieved in the related stage.

The four invariance stages stated in this article were analyzed in the order determined in the literature and the results were reported. All analyses were conducted using the Mplus 7.0 (Muthen \& Muthen, 1998-2020) software package. When comparing each stage to the previous, the change in model-data fit indexes were studied in addition to the likelihood ratio chi-square difference test, and $\triangle \mathrm{CFI}$ and $\triangle \mathrm{RMSEA}$ values were analyzed for instances where their values exceeded .01. All Mplus syntaxes (codes) are given in Appendix A.

\section{Participants}

Within the scope of this study, the longitudinal measurement invariance of the Social Presence Scale developed by Cakmak, Cebi and Kan (2014) was studied through repeated measurements. The study was conducted with the participation of learners in the Open Education System. Through experimental research, data was gathered at three-month intervals from 280 volunteer students. 


\section{FINDINGS}

Firstly, through this study, model data fit was obtained for configural invariance. As stated earlier, the testing of each stage requires that all parameters are freely estimated through configural invariance in both measurements. As such, the fit indices obtained are presented in table 2.

Table 2. Model-fit indexes of the configural invariance model

\begin{tabular}{cccc}
\hline Fit Index & Value & Goof Fit Cut-Off & Rationale \\
\hline X2/df & 1.98 & $<2.5$ & Tabachnick \& Fidell (2007) \\
RMSEA & $.062(.056-.067)$ & $<.08$ & Hooper et al. (2008) \\
CFI & .92 & $>.90$ & Hu \& Bentler (1999) \\
TLI & .89 & $>.90$ & Hooper et al. (2008) \\
SRMR & .061 & $<.08$ & Hu \& Bentler (1999) \\
\hline
\end{tabular}

The first value presented in Table 2 is obtained by dividing the chi-square value with the degrees of freedom. The expectation in structural equation modelling applications is that the difference between the chi-square values of the observed and expected correlation matrices would not be statistically significant. However, as chi-square values are influenced by sample size, they tend to yield statistical significance (Bentler \& Bonnet, 1980). Therefore, the value obtained by dividing the chi-square value with the degrees of freedom (df) is used. A resulting value below 2.5 is considered perfect fit (Tabachnick \& Fidell, 2008). The value of 1.98 obtained in this study is within the parameters of a perfect fit. An RMSEA value under .08 for the obtained fit indices is indicative of a good fit, while a value under .05 is indicative of a perfect model-data fit (Hooper et al., 2008). As such, it may be stated that the .062 value obtained indicates a good model-data fit. For CFI and TLI indexes, perfect model-data fit is accepted for values above .95 while .90 and above values are considered acceptable (Hu \& Bentler, 1999). Therefore, the .92 value obtained for CFI indicates good fit while the .89 value obtained for TLI is very close to the lower threshold. The evaluation of SRMR is approached in a manner similar to RMSEA; it may be stated that a value of .061 is indicative of a good model-data fit.

In light of these value obtained for model-data fit, it was observed that the model-data fit value for configural invariance, where all parameters are freely estimated in both measurements, was at an acceptable level. In other words, it was concluded that as the first stage of measurement invariance, configural invariance was achieved. In the second stage, values will be obtained for metric invariance and these values will be compared to the fit values obtained for configural invariance in the first stage.

The chi-square value obtained for metric invariance, which forces equal estimation of the factor loadings in both measurements, was subtracted from the chi-square value obtained for configural invariance (see Table 3 ), with the resulting 21.839 value being statistically insignificant at .05 for the difference in the degrees of freedom for both models, which was 14 . This value indicates no significant degradation in the model when the factor loadings are forced to be equally estimated in the measurements, in other words ensuring metric invariance. Similarly, the $\triangle$ RMSEA and $\triangle$ CFI values for both models were less than .01, which also indicates that metric invariance is achieved.

The third stage of measurement invariance is testing for scalar invariance. In the second row of Table 2, the differences between the chi-square and degrees of freedom for the scalar and metric invariance models are portrayed. The aim here is to test the scalar invariance based on the equal estimation of intercepts in both models. However, after entering the scalar invariance syntax, the analysis would not terminate without the iterations failing to complete due to the number of iterations being exceeded. This situation may be considered to be caused by the increasing complexity of the model and the sample size being relatively small for this complex model. To resolve this issue, the Bootstrap method was used. With this command, the analysis was repeated for 500 runs, and the degrees of freedom difference of the obtained chi-square difference was found to be statistically significant. At this point, the intercepts that interfere with invariance 
should be determined by observing modification indices. However, modifications are not accounted for when using the Bootstrap method in Mplus, and no other programs that resolve this issue exist. Therefore, this procedure could not be executed. Despite this setback, the change in the CFI and RMSEA values were observed to be lower than .01 , in other words the changes in these values were not statistically significant. In instance where the sample is relatively large and where the restrictions in the invariance stages cause significant degradation in model fit statistics, if there is no appreciable change in the practical fit indices, the researcher may prefer the more restricted model despite the worse statistical fit, due to its superior interpretive value (Widaman, Ferrer \& Conger, 2010). Based on this deliberation, it was concluded that the current situation did not hinder scalar invariance.

Table 3. Analysis results of longitudinal invariance

\begin{tabular}{cccc}
\hline Invariance Stage & $\boldsymbol{\Delta \times 2 ( d f )}$ & $\boldsymbol{\Delta R M S E A}$ & $\boldsymbol{\Delta C F I}$ \\
\hline Configural - Metric & $21.84(14)$ & $<.01$ & $<.01$ \\
Metric - Scalar & $23.17(12)^{*}$ & $<.01$ & $<.01$ \\
Scalar - Strict & $29,73(20)$ & $<.01$ & $<.01$ \\
\hline
\end{tabular}

${ }^{*} p<.05$

In the final stage, strict invariance was tested. The difference of 29.73 obtained with the chi-square from the previous stage (see Table 3) was found to be statistically insignificant in 20 degrees of freedom. Supporting this situation, the $\triangle \mathrm{CFI}$ and $\triangle \mathrm{RMSEA}$ values were observed to be under .01. In other words, it was concluded that strict invariance was achieved.

Within the scope of this study, no instances in which the longitudinal invariance of the Social Presence Scale was questionable were encountered. Despite increased restrictions during each stage of testing, no significant changes were recorded in the model-data fits. However, the lack of modifications as a result of utilizing Bootstrap enforces a limitation on this study in that no inferences could be made regarding the intersection points as the probably source of any possible significant difference between the metric and scalar models. In general, it may be stated that there are no impediments to the comparison of pre-post test differences through repeated measurements.

\section{DISCUSSIONS AND CONCLUSION}

Self-report questionnaires are still frequently used in various fields of social sciences. When conducting the validity analysis of these measurement tools, only the basic factor analytic applications are often conducted when testing construct validity. Most simplistically, the equivalence between groups of the latent structure trying to be measured - the measurement invariance - should be examined before, for example, testing differentiation based on gender. Otherwise, the source of any potential difference that emerges, whether the difference is truly from group association or due to the scale working differently for two groups, cannot be determined. Similarly, especially with experimental studies, when a scale is applied to a group in certain time intervals, the difference between these measurements must be tested in advance to ascertain the function of the experimental study, which requires that the measurement tool is interpreted and works identically on individuals in both measurements through the establishment of longitudinal invariance. In this study, data gathered from the Social Presence Scale applied in an experiment conducted within a course in the Open Education System was used, with the application of the scale being repeated at two different times for the analysis of longitudinal invariance. Measurement invariance is achieved by testing the four stages concurred upon in the literature. As such, if the model-data fit statistics obtained for the first stage of configural invariance are good, the model is restricted in each subsequent stage, and no statistically significant degradation is expected to occur as a result of these restrictions if invariance is achieved. Following this process, configural invariance for the Social Presence Scale was achieved, and it was determined that 
the restrictions applied as required by the invariance model in each subsequent stage did not significantly degrade the model compared to the previous stage. Combining all these results, it was concluded that the scale achieved longitudinal invariance.

Various decisions, acceptance or rejection of hypotheses, or new decisions by policymakers are all likely based on results obtained by measurement tools. Therefore, for all studies to be able to rely on the data obtained from measurement tools, they must ensure that these tools measure the latent variable they aim to measure. In this process that requires the determination of structural validity, the need to test the structural equivalence of data obtained from different groups or measurements is often neglected and possibly lesserknown. It is believed that this study may provide an example for research regarding establishing construct validity in data-gathering processes in the field of open and distance learning. The findings of this study are significant in ensuring that the results obtained from the social presence scale, which is an important scale used in open and distance learning environments, are obtained purposefully. In accordance with the findings of this study, the contribution of the experiment to social presence can be measured more accurately and reliably in experimental studies, ensuring researchers achieving more accurate findings based on these results.

\section{RECOMMENDATIONS}

\section{Recommendations from the Study}

Measurement invariance studies consist of models that increase in complexity in each stage. Therefore, it is possible that iterations occasionally do not occur. It is therefore recommended that researchers take this into consideration and conduct their analyses with relatively large sample sizes.

\section{Recommendations for Researchers}

It is noted that longitudinal invariance is often neglected in longitudinal research based on repeated measurements. It is recommended that researchers gain awareness in this regard and report invariance in similar studies.

The reporting of invariance results of studies where the number of measurement repetitions (three, four, ...) may better portray the possible influence of time on invariance status.

In instances where within the scope of the study data is accepted as ordinal rather than continuous, the comparison of the analyses conducted with different estimation methods - primarily WLSMV - with these findings may contribute to the literature.

The scale used in this study has been verified in accordance with the correlated traits factor model. The conclusion of the invariance processes of this scale based on other factor analytic models such as secondorder and bifactor may be studied.

Similarly, the traditional methods obtained in this study may be compared with invariance methods based on exploratory structural equation modelling, and the result may prove interesting.

Researchers in the field of open and distance learning must conduct longitudinal invariance studies on the various important scales in the field in addition to the social presence scale such as; the sense of community scale/index, learner satisfaction index, transactional distance scale, learner attitude scale, self-directed learning skills index, and many other scales and indexes. This would ensure that the findings obtained from the use of scales in the field of open and distance learning are more accurate. 


\title{
BIODATA and CONTACT ADDRESSES of AUTHORS
}

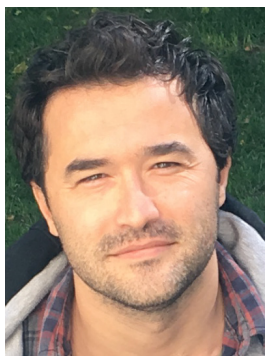

Dr. Murat Dogan SAHIN is a Assistant Professor at the Faculty of Education, Anadolu University. He received both his Masters and Doctorate degrees in the field of Educational Measurement and Evaluation from the Hacettepe University Institute of Educational Sciences. His research areas focuses on computerized adaptive and multistage testing, structural equation modeling, statistical learning and psychometrics.

Murat Dogan SAHIN

Faculty of Education

Address: Anadolu University, Education Faculty, Eskisehir, Turkey

Phone: +90 2223350580/3470

E-mail: mdsahin@anadolu.edu.tr

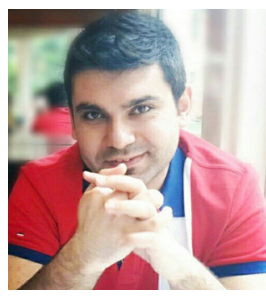

Dr. Hakan KILINC is currently working as a research assistant doctor of Open and Distance Education at Open Education Faculty, Anadolu University. He undertook undergraduate studies in the feld of Computer Education and Instructional Technologies (CEIT) between the years of 2009 and 2013 at Anadolu University. He received his master degree in the feld of Distance Education in 2016, May. In addition to this, he received his Ph.D. Degree in the feld of Distance Education in 2020, April. Hakan Kilinc continues to work in the feld of distance education technology, personalized learning environments, information and communication technologies, synchronous, asynchronous, and interactive communications, learner-generated content and online group discussions.

\section{Hakan KILINC}

Open Education Faculty

Address: Anadolu University, Open Education Faculty, Eskisehir, Turkey

Phone: +90 2223350580/2773

E-mail: hakankilinc@anadolu.edu.tr

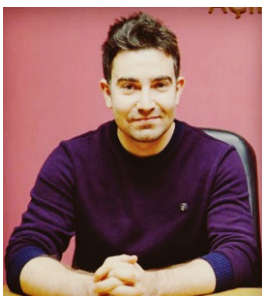

Dr. Hakan ALTINPULLUK is an Assistant Professor of Open and Distance Education at Open Education Faculty, Anadolu University. He undertook undergraduate studies in the field of Computer Education and Instructional Technologies (CEIT) between the years of 2005 and 2009 at Anadolu University. He received his Ph.D. Degree in the field of Distance Education in 2018. Hakan Altinpulluk continues to work in the field of Open and Distance Education, Augmented Reality, Virtual Reality, Mobile Learning, Mobile Health, Massive Open Online Courses, Learning Management Systems, Open Educational Resources, Personal Learning Environments, and E-Learning Systems.

\author{
Hakan ALTINPULLUK \\ Open Education Faculty \\ Address: Anadolu University, Open Education Faculty, Eskisehir, Turkey \\ Phone: +90 2223350580/2450 \\ E-mail: hakanaltinpulluk@anadolu.edu.tr
}




\section{REFERENCES}

Akcaoglu, M., \& Lee, E. (2016). Increasing social presence in online learning through small group discussions. The International Review of Research in Open and Distributed Learning, 17(3). Doi: 10.19173/irrodl.v17i3.2293

Annand, D. (2011). Social presence within the community of inquiry framework. The International Review of Research in Open and Distributed Learning, 12(5), 40-56. Doi: 10.19173/irrodl.v12i5.924

Basusta, N.B.U. (2010). Olcme esdegerligi. Egitimde ve Psikolojide Olcme ve Degerlendirme Dergisi, 1(2), 58-64.

Bentler, P.M., \& Bonnet, D.C. (1980). Significance tests and goodness of fit in the analysis of covariance structures. Psychological Bulletin, 88(3), 588-606.

Borup, J., West, R. E., \& Graham, C. R. (2012). Improving online social presence through asynchronous video. The Internet and Higher Education, 15(3), 195-203. Doi: 10.1016/j.iheduc.2011.11.001

Boston, W., Diaz, S. R., Gibson, A. M., Ice, P., Richardson, J., \& Swan, K. (2009). An exploration of the relationship between indicators of the community of inquiry framework and retention in online programs. Journal of Asynchronous Learning Networks, 13(3).

Cakmak, E. K., Cebi, A., \& Kan, A. (2014). E-ogrenme ortamlarina yonelik "sosyal bulunusluk olcegi" gelistirme calismasi. Kuram ve Uygulamada Egitim Bilimleri, 14(2), 755-768. Doi: 10.12738/ estp.2014.2.1847

Chen F.F., Sousa K.H. \& West SG. (2005). Testing measurement invariance of second-order factor models. Structural Equation Modeling, 14, 471-492. Doi: 10.1207/s15328007sem1203_7

Cheung, G. W., \& Rensvold, R. B. (2002) Evaluating goodness-of-fit indexes for testing measurement invariance. Structural Equation Modeling, 9(2), 233-255. Doi: 10.1207/S15328007SEM0902_5

Cheung, G.W., \& Rensvold R.B. (1999). Testing factorial invariance across groups: A reconceptualization and proposed new method. Journal of Management, 25, 1-27.

Cobb, S. C. (2009). Social presence and online learning: A current view from a research perspective. Journal of Interactive Online Learning, 8(3), 241-254.

Dimitrov, D. D. (2010). Testing for factorial invariance in the context of construct validation. Measurement and Evaluation in Counseling and Development, 43(2). 121-149. Doi: 10.1177/0748175610373459

Elcicek, M., Erdemci, H., \& Karal, H. (2018). Examining the relationship between the levels of digital citizenship and social presence for the graduate students having online education. Turkish Online Journal of Distance Education, 19(1), 203-214. Doi: 10.17718/tojde.382801

Ercan, Y., \& Bulbul, T. (2019). Uzaktan egitim ortamlarinda iletisimci bicimlerinin sosyal buradaliga etkisi. Trakya University Journal of Social Science, 21(2). Doi: 10.26468/trakyasobed.630333

Ferrer E., Balluerka N., \& Widaman K.F. (2008). Factorial invariance and the specification of second-order latent growth models. Methodology, 4, 22-36. Doi: 10.1027/1614-2241.4.1.22

Garrison, D. R. (2011). E-learning in the 21st century: A framework for research and practice. Routledge.

Garrison, D. R., \& Akyol, Z. (2013). The community of inquiry theoretical framework. G. M. Moore (Ed.), Handbook of distance education (pp. 104-120). New York, NY: Routledge.

Hooper, D., Coughlan, J., \& Mullen, M.R. (2008). Structural equation modelling: Guidelines for determining model fit. Electronic Journal of Business Research Methods, 6(1), 53-60.

Horzum, M. B. (2015). Interaction, structure, social presence, and satisfaction in online learning. Eurasia Journal of Mathematics, Science \& Technology Education, 11(3). Doi: 10.12973/eurasia.2014.1324a

Hostetter, C. (2013). Community matters: Social presence and learning outcomes. Journal of the Scholarship of Teaching and Learning, 13(1), 77-86. 
Hostetter, C., \& Busch, M. (2006). Measuring up online: The relationship between social presence and student learning satisfaction. Journal of the Scholarship of Teaching and Learning, 1-12.

Hu, L.T., \& Bentler, P.M. (1999). Cutoff criteria for fit indexes in covariance structure analysis: Conventional criteria versus new alternatives. Structural Equation Modeling, 6(1), 1-55. Doi: $10.1080 / 10705519909540118$

Joksimovic, S., Gasevic, D., Kovanovic, V., Riecke, B. E., \& Hatala, M. (2015). Social presence in online discussions as a process predictor of academic performance. Journal of Computer Assisted Learning, 31(6), 638-654. Doi: 10.1111/jcal.12107

Jorge, I. (2010). Social presence and cognitive presence in an online training program for teachers of Portuguese: Relation and methodological issues. IODL and ICEM 2010 Joint Conference and Media Days, (pp.427-435).

Kang, M., \& Im, T. (2013). Factors of learner-instructor interaction which predict perceived learning outcomes in online learning environment. Journal of Computer Assisted Learning, 29(3), 292-301. Doi: $10.1111 /$ jcal.12005

Kilinc, H. (2020). Cevrimici grup tartismalarinin ogrenenler uzerindeki etkisinin cesitli degiskenler acisindan incelenmesi: Anadolu Universitesi Acikogretim Fakultesi ornegi. Unpublished doctoral thesis. Anadolu University, Institute of Social Science, Eskisehir.

Kreijns, K., Van Acker, F., Vermeulen, M., \& Van Buuren, H. (2014). Community of inquiry: Social presence revisited. E-learning and Digital Media, 11(1), 5-18. Doi: 10.2304/elea.2014.11.1.5

Little T.D. (1997). Mean and covariance structures (MACS) analyses of cross-cultural data: Practical and theoretical issues. Multivariate BehavioralResearch,32,53-76.Doi:10.1207/s15327906mbr3201_3

Lowenthal, P. R. (2010). The evolution and influence of social presence theory on online learning. T. T. Kidd (Ed.), Online Education and Adult Learning: New Frontiers for Teaching Practices. Hershey, PA: IGI Global.

Marsh, A.J.S., Parker, P.D., \& Morin, A.J.S. (2015). Invariance testing across samples and time: Cohort sequence analysis of perceived body composition. In N. Ntoumanis, \& N. Myers (Eds.), An Introduction to Intermediate and Advanced Statistical Analyses for Sport and Exercise Scientists. Wiley.

Matanaghi, A. (2015). Online learning readiness level and perceived social presence of the teacher candidate's in the online learning environment an EMU Example. (Master's thesis, Eastern Mediterranean University (EMU)-Dogu Akdeniz Universitesi (DAU)).

Millsap, R.E. \& Meredith, W. (2007). Factorial invariance: Historical perspectives and new problems. Factor Analysis At 100: Historical Developments and New Directions. Mahwah, NJ: Erlbaum.

Muthen, L. K., \& Muthen, B. O. (1998-2020). Mplus User's Guide. Sixth Edition. Los Angeles, CA: Muthen $\&$ Muthen.

Nesselroade, J.R. (1983). Temporal selection and factor invariance in the study of development and change. Life-Span Development and Behavior. New York: Academic Press.

Oztok, M., \& Brett, C. (2011). Social presence and online learning: A review of research. International Journal of E-Learning \& Distance Education, 25(3).

Putnick D. L., \& Bornstein, M. H. (2016). Measurement invariance conventions and reporting: The state of the art and future directions for psychological research. Developmental Review, 41, 71-90. Doi: $10.1016 / j . d r .2016 .06 .004$

Rensvold R.B., \& Cheung G.W. (1998). Testing measurement model for factorial invariance: A systematic approach. Educational and Psychological Measurement, 58, 1017-1034. Doi: $10.1177 / 0013164498058006010$

Richardson, J., \& Swan, K. (2003). Examing social presence in online courses in relation to students' perceived learning and satisfaction. Journal of Asynchronus Learning Networks. 7(1), 68-88. 
Russo, T. C., \& Benson, S. (2005). Learning with invisible others: Perceptions of online presence and their relationship to cognitive and affective learning. International Forum of Educational Technology and Society. 8(1), 54-62.

Strong, R., Irby, T. L., Wynn, J. T., \& McClure, M. M. (2012). Investigating students' satisfaction with elearning courses: the effect of learning environment and social presence. Journal of Agricultural Education, 53(3), 98-110. Doi: 10.5032/jae.2012.03098

Tabachnick, B.G., \& Fidell, L.S. (2008). Using multivariate statistics. New York: Allyn and Bacon.

Vandenberg, R. J., \& Lance, C. E. (2000). A review and synthesis of the measurement invariance literature: Suggestions, practices, and recommendations for organizational research. Organizational Research Methods, 3, 4-70.

Whiteside, A. L. (2015). Introducing the social presence model to explore online and blended learning experiences. Online Learning, 19(2).

Widaman, K. F., \& Reise, S. P. (1997). Exploring the measurement invariance of psychological instruments: Applications in the substance use domain. In K. J. Bryant, M. Windle, \& S. G. West (Eds.), The science of prevention: Methodological advances from alcohol and substance abuse research (pp. 281324). Washington, DC, US: American Psychological Association.

Widaman, K. F., Ferrer, E., \& Conger, R. D. (2010). Factorial invariance within longitudinal structural equation models: Measuring the same construct across time. Child Development Perspectives, 4(1), 10-18. Doi: 10.1111/j.1750-8606.2009.00110.x 


\section{APPENDIX A}

Mplus Syntax for Testing the Longitudinal Invariance of the Three Dimensional Scale

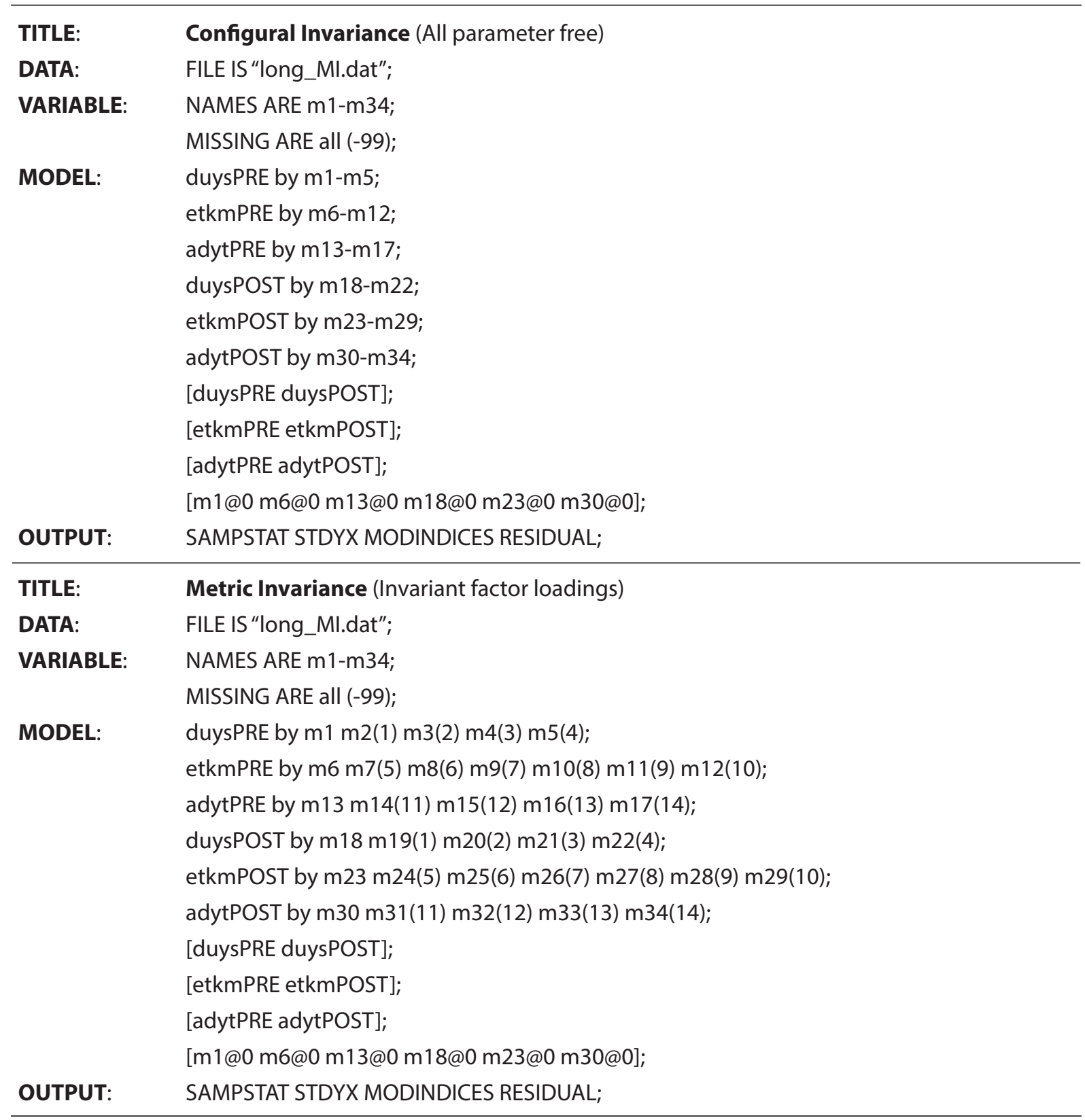




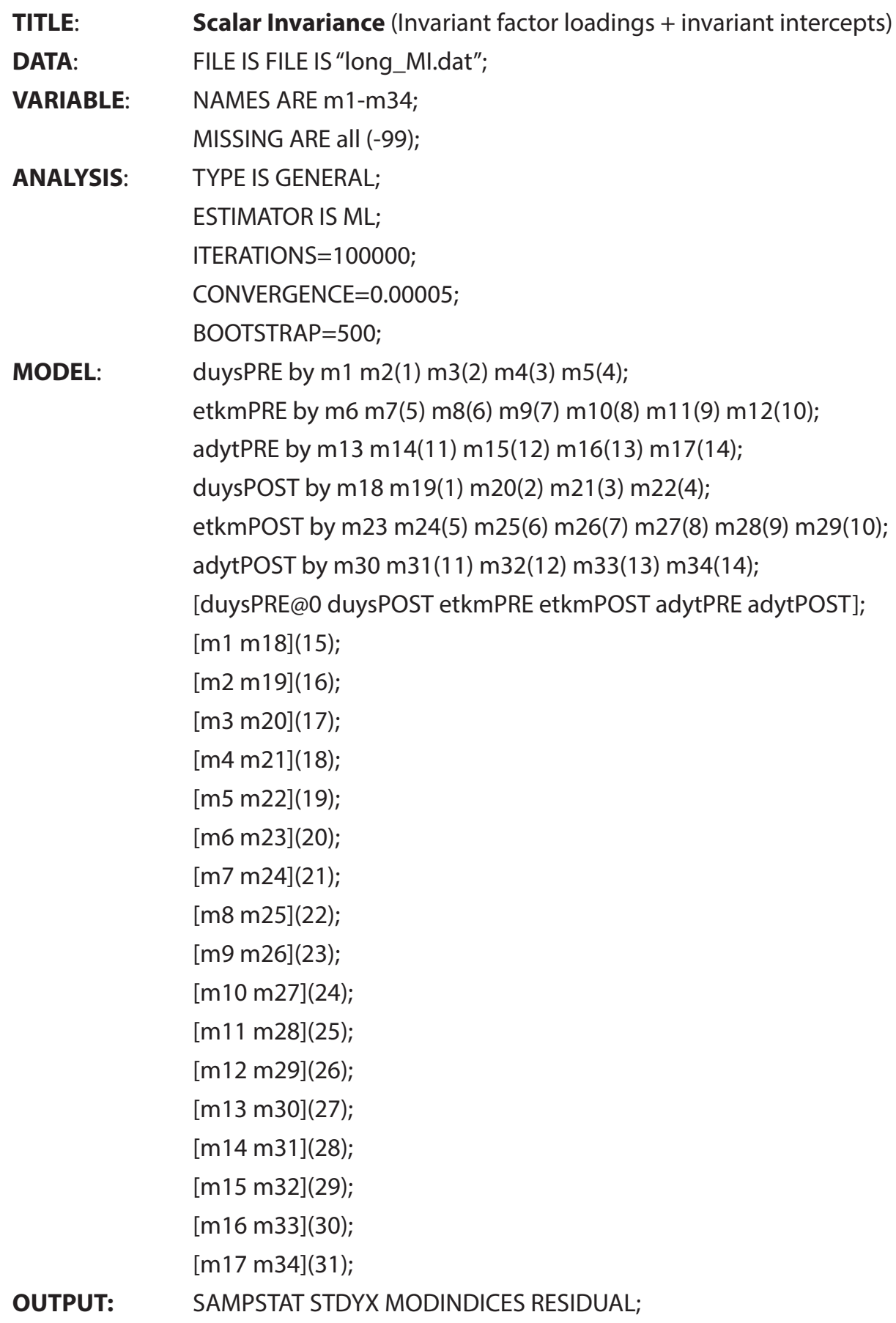




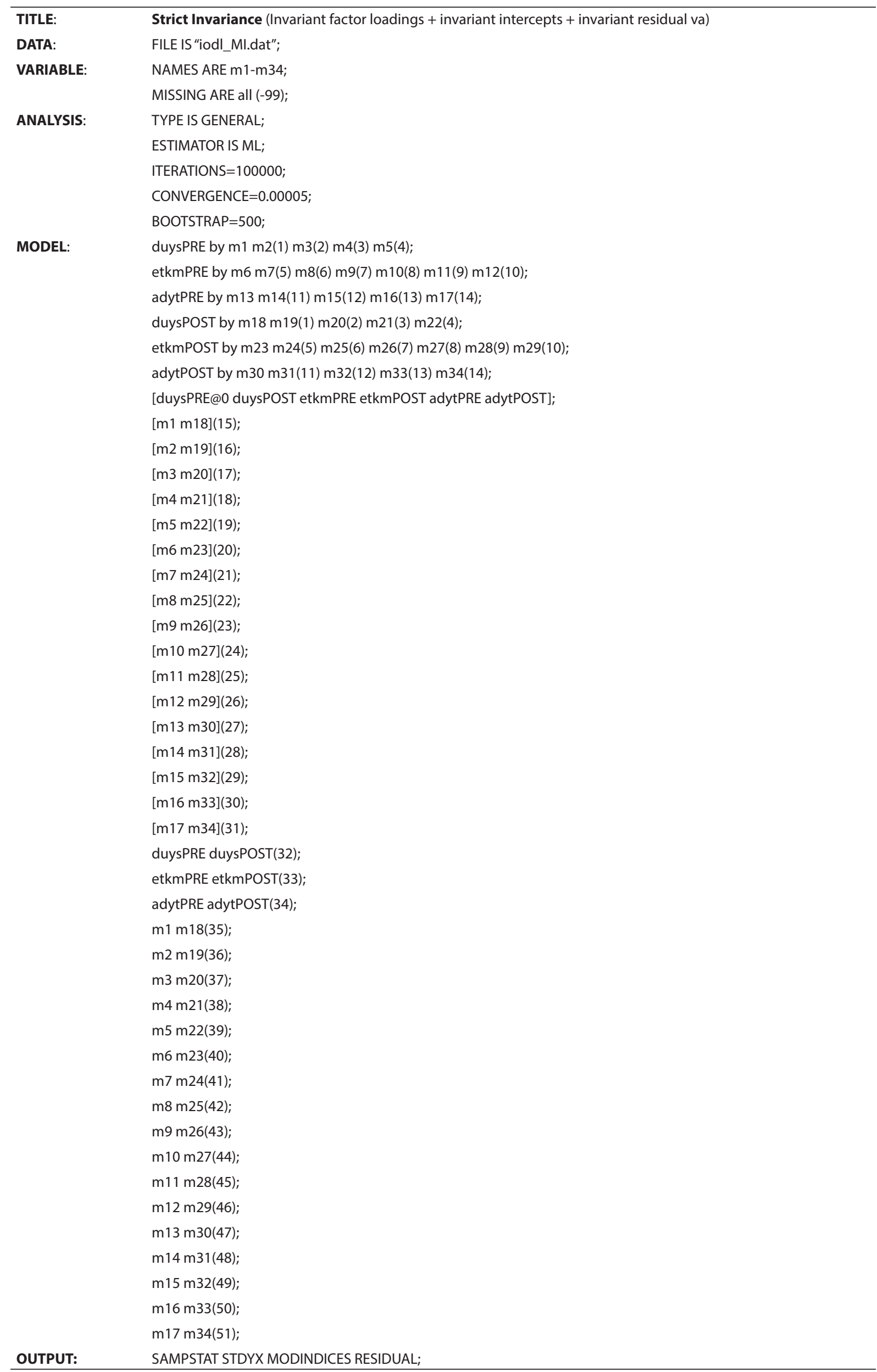

